\title{
Osteochondral autograft transplantation of the femoral head in sequelae of developmental dysplasia of hip: A case report and review of the literature
}

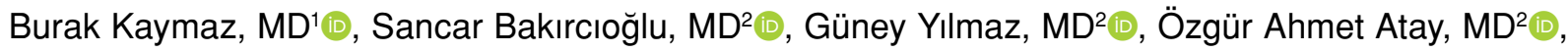 \\ Mehmet Cemalettin Aksoy, MD²D \\ ${ }^{1}$ Department of Orthopedics and Traumatology, Medicine Faculty of Çanakkale Onsekiz Mart University, Çanakkale, Turkey \\ 2Department of Orthopedics and Traumatology, Medicine Faculty of Hacettepe University, Ankara, Turkey
}

Avascular necrosis (AVN) of the femoral head is one of the most common complications after treatment for developmental dysplasia of the hip (DDH). Depending on the type and severity of AVN, the femoral head loses its round shape which can also compromise acetabular development. Deformed head may cause femoroacetabular impingement and chondral lesions and degenerative joint disease may arise. ${ }^{[1]}$

For older patients, total hip arthroplasty is the most effective treatment option; however, this is often not feasible for young and active patients. Recently, salvage of the young adult hip with deformed femoral head has been forwarded. ${ }^{[2]}$ Ganz et al. ${ }^{[3]}$ have demonstrated that their surgical approach to the hip with dislocation and osteochondroplasty of

Received: April 08, 2020

Accepted: May 05, 2020

Published online: September 11, 2020

Correspondence: Güney Yılmaz, MD. Hacettepe Üniversitesi Tıp Fakültesi Ortopedi ve Travmatoloji Anabilim Dalı, 06100 Sıhhiye, Ankara, Türkiye.

E-mail: aflguney@hotmail.com

Doi: 10.5606/ehc.2020.75135

Citation: Kaymaz B, Bakırcıoğlu S, Yılmaz G, Atay ÖA, Aksoy MC. Osteochondral autograft transplantation of the femoral head in sequelae of developmental dysplasia of hip: A case report and review of the literature. Jt Dis Relat Surg 2020;31(3):619-625.

(O2020 All right reserved by the Turkish Joint Diseases Foundation

This is an open access article under the terms of the Creative Commons Attribution-NonCommercial License, which permits use, distribution and reproduction in any medium, provided the original work is properly cited and is not used for commercial purposes (http://creativecommons.org/licenses/by-nc/4.0/).

\section{ABSTRACT}

Although osteochondral autograft transplantation (OAT) in the knee and ankle has gained much popularity on the other hand the technique has rarely been applied in the femoral head. In this article, we present a 15 -year-old female patient with unstable chondral lesion on the right femoral head. She had a history of open reduction for developmental dysplasia which resulted in avascular necrosis. She had coxa magna, breva and trochanteric overgrowth along with an unstable chondral lesion on the superolateral part of the femoral head. She underwent OAT for chondral lesion, femoral head reshaping and relative neck lengthening. Her Harris Hip Score improved from 55 to 90 in the 18 months of follow-up. The case is unique in a way that the autografts were harvested from the anterior part of the same femoral head that was already intended to be removed during osteochondroplasty.

Keywords: Femoral head, hip dysplasia, osteochondral autograft, surgical hip dislocation.

the head-neck junction can be applied with favorable results.

Treatment of chondral lesions of the hip joint is problematic due to the deep anatomy and complex biomechanical demands. ${ }^{[4,5]}$ Several treatment methods have been adapted from the knee joint; however, the biomechanics and anatomy of the hip joint are different from the knee. ${ }^{[6,7]}$ Autologous osteochondral grafting is a well-described treatment option for full thickness cartilage lesions particularly in the knee and ankle. However, the results of osteochondral autograft transplantation (OAT) for femoral head cartilage lesions are not well known. ${ }^{[8]}$

In this case report, we present the surgical technique of OAT in a patient with severe hip pain and catching due to osteochondral lesion of the femoral head. The deformed femoral head with large 
cartilage defect was treated successfully with surgical hip dislocation, OAT, osteochondroplasty and relative neck lengthening. The case differs from the other case reports in the literature since the etiology was hip dysplasia and the osteochondral grafts were harvested from the removed part of the same femoral head during osteochondroplasty. ${ }^{[0]}$

\section{CASE REPORT}

A 15-year-old girl patient presented to the outpatient clinic with the complaints of pain, catching and locking in her right hip. She had limping and limited hip range of motion. The patient's past surgical history included an open reduction for DDH when she was 18 months of age. On physical examination, the patient was limping and hip movements were restricted, painful at the limits of the abduction and internal rotation. The impingement sign was positive. Plain radiographs were obtained and deformed femoral head with sagging rope sign was noted. The femoral neck was short and trochanteric overgrowth was noted (Figure 1a, b). Computed tomography and magnetic resonance imaging (MRI) scans confirmed the osteochondral lesion located on the superolateral and central part of the femoral head (Figure 1c, d). The preoperative Harris Hip Score (HHS) of the patient was 55. Patient was thought to be a good candidate for either to repair or reconstruct the osteochondral lesion, reshaping of the femoral head and relative neck lengthening for trochanteric overgrowth. With this surgical plan, she was scheduled for surgical hip dislocation. A written informed consent was obtained from the legal guardian of the patient.

General anesthesia was applied and she was placed in the lateral decubitus position. A standard safe surgical dislocation of the right hip was performed as described by Ganz et al. ${ }^{[3]}$ Special attention was given to identifying femoral head-neck morphology including offset, as well as severity and location of damage to the femoral and acetabular articular cartilage and the acetabular labrum. Approximately $2 \times 3 \mathrm{~cm}$ chondral lesion of the femoral head was confirmed intraoperatively (Figure 2a). The fragment was
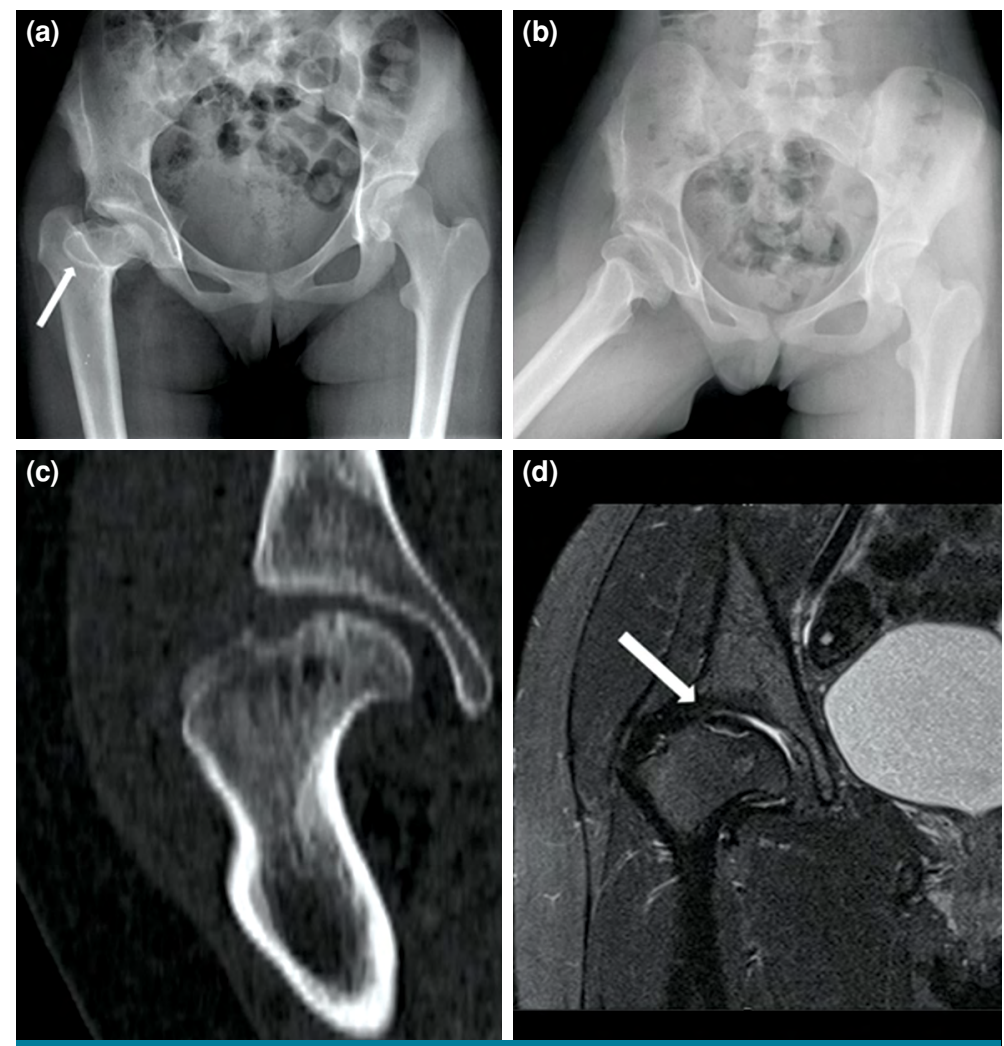

FIGURE 1. (a, b) Preoperative plain anteroposterior radiograph showing trochanteric overgrowth, short femoral neck, sagging rop sign (white arrow). (c) Coronal computed tomography scan indicating superolateral chondral defect. (d) Coronal magnetic resonance imaging showing unstable superolateral chondral fragment (white arrow). 

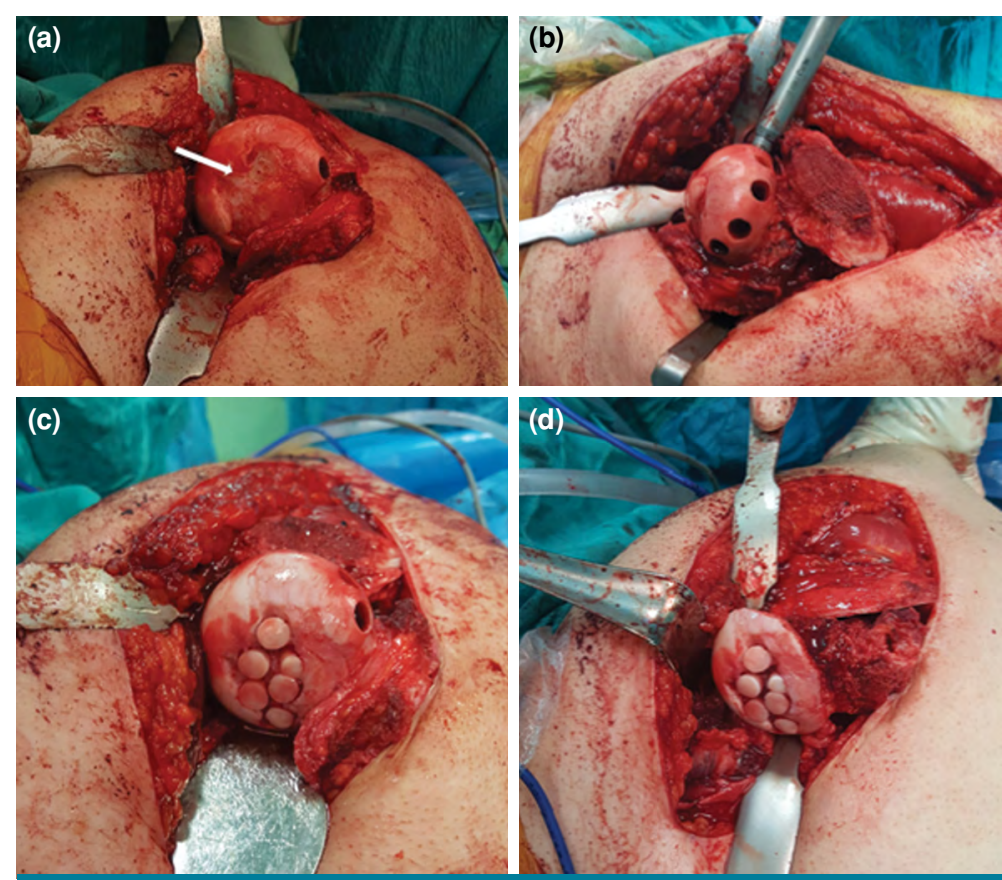

FIGURE 2. (a) Intraoperative picture of femoral head showing (white arrow) chondral defect. (b) Autografts were harvested from anterior-inferior part of femoral head. (c) Defect was replaced with five $8 \mathrm{~mm}$ and one $6 \mathrm{~mm}$ autografts. (d) Femoral head was reshaped and stable trochanteric fragment was trimmed away.

unstable and avascular. So, a reconstruction type procedure (OAT) was opted rather than fixation. The labrum was intact. Chondral lesion was debrided. Anterolateral aspect of aspheric femoral head which was planned to be removed to improve femoral head morphology was used for graft harvesting (Figure 2b). Osteochondral autograft transplantation was performed with six plugs (five $8 \mathrm{~mm}$ and one $6 \mathrm{~mm}$; DePuy osteochondral autograft transplantation system, DePuy Mitek Inc., Raynham, Massachusetts, USA) (Figure 2c). Attention was given to reconstruct the roundness of the femoral head by altering the deepness of the recipient holes and osteochondral fragments in the
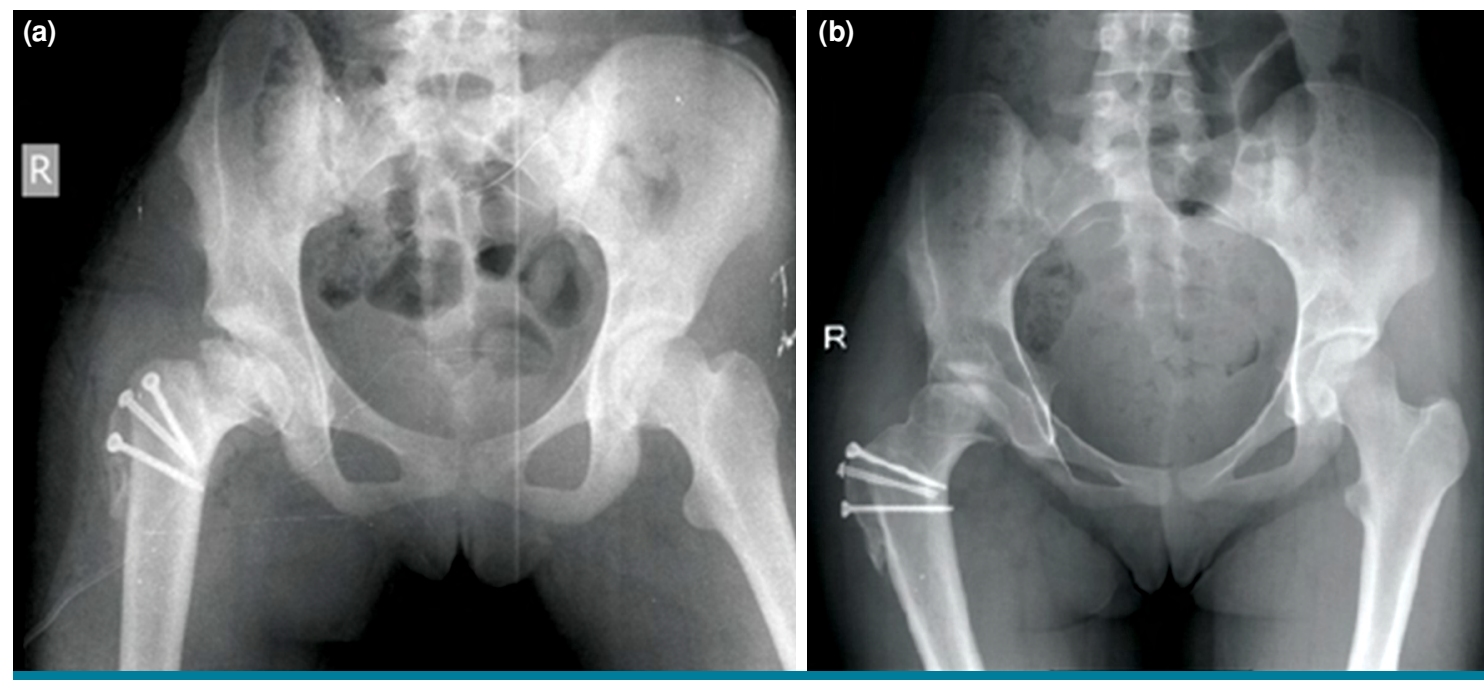

FIGURE 3. Postoperative immediate (a) and sixth-month follow-up (b) plain radiographs showing relative neck lengthening and healed trochanter major. 

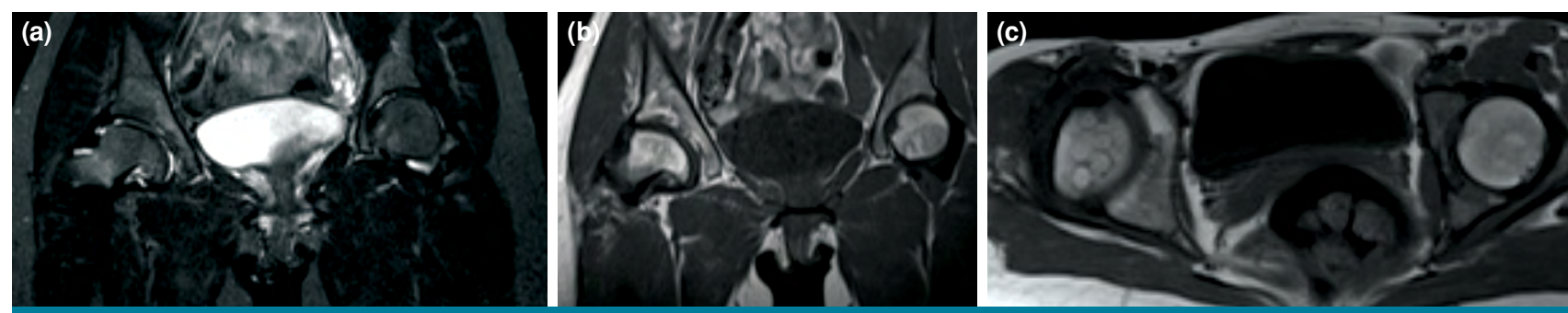

FIGURE 4. (a, b) Magnetic resonance imaging of right hip after 18 months indicates a descent integration of plugs and slight chondral step-off. (c) Axial plane section shows bone plugs used for mosaicplasty.

donor site. Next, the femoral head-neck junction was debrided utilizing osteotomes and a highspeed burr to improve offset (osteochondroplasty) (Figure 2d). The femoral head was reduced and presence of impingement was confirmed. Then, the extended posterior retinacular flap which contains the deep branch of the medial femoral circumflex artery was developed after incomplete osteotomy of the posterior part of the stable trochanter. After the flap was composed, posterosuperior part of the stable trochanter was trimmed away until the level of the superior femoral neck (Figure $2 \mathrm{~d}$ ). The capsule was repaired. The trochanteric fragment was advanced distally. When a satisfactory increase in the head center-trochanteric distance was accomplished, the trochanteric fragment was fixed with $4.5 \mathrm{~mm}$ cannulated and cortical screws. With trochanteric advancement, improvement of abductor lever arm along with relative femoral neck lengthening was accomplished (Figure 3).

Range of motion exercises using continuous passive motion and quadriceps strengthening exercises were initiated in the postoperative period. A maximum $90^{\circ}$ of hip flexion was allowed for the first three weeks. Active abduction was prohibited for six weeks and the patient was instructed nonweight-bearing mobilization for three months. No complications were encountered during the postoperative period. In the third month control, the hip pain was decreased significantly. She had no complaint of locking in her hip joint. Hip movements were pain free even at the limits of the abduction, flexion and internal rotation. She was allowed to walk without crutches. Harris Hip Score increased to 90, she had no hip pain, her limping was improved, the trochanteric fragment was healed and she was satisfied with her result. After 18 months of followup, control MRI of the right hip indicated integration of the osteochondral plugs with no significant femoral head step-off (Figure 4).

\section{DISCUSSION}

Depending on its severity, AVN of the femoral head causes different deformities. Deformed head may cause femoracetabular impingement, chondral lesions, degenerative joint disease and abnormal gait. ${ }^{[1,10,1]}$ Surgical dislocation and osteochondroplasty with trochanteric advancement addresses the pathologic femoral head morphology and improves the abductor lever arm. ${ }^{[12]}$

Osteochondral autograft transplantation was first described by Hangodyand Füles ${ }^{[13]}$ and gained popularity to treat cartilage defects in the knee and ankle. The procedure aims to replace the damaged hyaline cartilage with healthy hyaline cartilage harvested from a nonweight-bearing portion of the knee joint. ${ }^{[14]}$

Although OAT in the knee and ankle has gained much popularity, the technique has rarely been applied in the femoral head (Table I). ${ }^{[15-17]}$ Nam et al. ${ }^{[15]}$ reported two cases with femoral head chondral defects after traumatic hip dislocation which were treated with osteochondral plugs harvested from the knee and inferior portion of the femoral head. Hart et al. ${ }^{[16]}$ reported a case in which a defect of 16 $\mathrm{mm}$ of the femoral head due to a penetrating screw was treated with OAT from the ipsilateral lateral femoral condyle. But they used a posterior approach and did not dislocate the hip which is different from our case. Gagala et al. ${ }^{[17]}$ reported OAT for femoral head AVN by surgical dislocation in 20 patients and stated that OAT was a successful treatment method at precollapse stage. Anthonissen et al. ${ }^{[18]}$ reported OAT for the treatment of a large defect $(2 \times 2.5 \mathrm{~cm})$ due to trauma with good outcome.

There is limited literature regarding osteochondroplasty together with OAT. Güngör et al. ${ }^{[19]}$ reported osteochondral OAT along with osteochondroplasty of the femoral head in femoroacetabular impingement in two patients. Patients received surgical dislocation and 


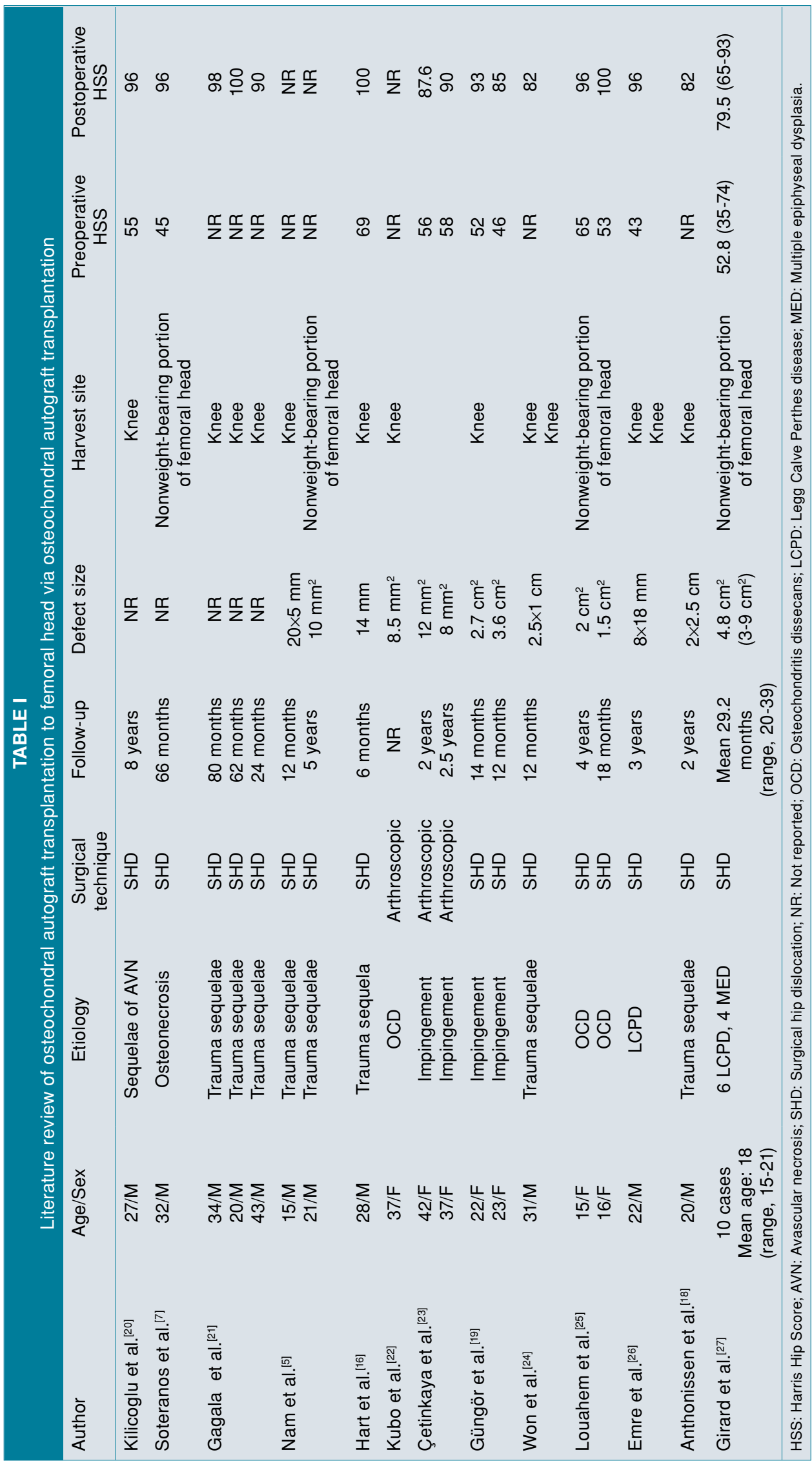


osteochondral cylinders for OAT were removed from the ipsilateral knee.

Our patient had an unstable cartilage fragment in a large area at the weight-bearing zone of the femoral head. The fragment was avascular and had no bony connection with femoral head. We believed that fixation of the fragment or a valgus producing osteotomy of the proximal femur in order to move the defective area out of weight-bearing zone would not achieve satisfactory result. The patient had a large femoral head due to previous AVN which was more apparent in the anterior part. We opted to treat the cartilage defect with OAT and used the anterior aspect of aspheric femoral head as a donor site. The anterolateral part of the head was planned to be removed for femoral head reshaping. We obtained autografts with a diameter of $8 \mathrm{~mm}$ (five) and $6 \mathrm{~mm}$ (one) from the anterolateral part of the same femoral head. Our case is unique in the literature since the removed part of femoral head was used as a donor site for osteochondral grafts. So, the patient was saved from an unnecessary knee procedure. The patient also had osteochondroplasty and relative neck lengthening along with OAT. In addition, etiologies for OAT in the literature include Legg Calve Perthes disease, epiphyseal dysplasia, osteochondritis dissecans or trauma. Our case had sequelae of DDH and differs in terms of etiology.

In conclusion, safe surgical hip dislocation has changed the treatment approaches for many hip pathologies in young adults. As a result, we believe that OAT is an effective treatment method for osteochondral lesions of the femoral head. Although the most common source of the autograft is the knee, aspheric portion of the femoral head can also be used in selected cases and an unnecessary knee surgery can be avoided.

\section{Declaration of conflicting interests}

The authors declared no conflicts of interest with respect to the authorship and/or publication of this article.

\section{Funding}

The authors received no financial support for the research and/or authorship of this article.

\section{REFERENCES}

1. Brougham DI, Broughton NS, Cole WG, Menelaus MB. Avascular necrosis following closed reduction of congenital dislocation of the hip. Review of influencing factors and long-term follow-up. J Bone Joint Surg [Br] 1990;72:557-62.

2. Clohisy JC, Keeney JA, Schoenecker PL. Preliminary assessment and treatment guidelines for hip disorders in young adults. Clin Orthop Relat Res 2005;441:168-79.
3. Ganz R, Gill TJ, Gautier E, Ganz K, Krügel N, Berlemann U. Surgical dislocation of the adult hip a technique with full access to the femoral head and acetabulum without the risk of avascular necrosis. J Bone Joint Surg [Br] 2001;83:1119-24.

4. Bowman KF Jr, Fox J, Sekiya JK. A clinically relevant review of hip biomechanics. Arthroscopy 2010;26:1118-29.

5. D'Lima DD, Fregly BJ, Colwell CW Jr. Implantable sensor technology: measuring bone and joint biomechanics of daily life in vivo. Arthritis Res Ther 2013;15:203.

6. McDonald JE, Herzog MM, Philippon MJ. Return to play after hip arthroscopy with microfracture in elite athletes. Arthroscopy 2013;29:330-5.

7. Sotereanos NG, DeMeo PJ, Hughes TB, Bargiotas K, Wohlrab D. Autogenous osteochondral transfer in the femoral head after osteonecrosis. Orthopedics 2008;31:177.

8. Jordan MA, Van Thiel GS, Chahal J, Nho SJ. Operative treatment of chondral defects in the hip joint: a systematic review. Curr Rev Musculoskelet Med 2012;5:244-53.

9. Atik OŞ. Is there something new and interesting in my article? Eklem Hastalik Cerrahisi 2019;30:69.

10. Gage JR, Winter RB. Avascular necrosis of the capital femoral epiphysis as a complication of closed reduction of congenital dislocation of the hip. A critical review of twenty years' experience at Gillette Children's Hospital. J Bone Joint Surg [Am] 1972;54:373-88.

11. Salter RB, Kostuik J, Dallas S. Avascular necrosis of the femoral head as a complication of treatment for congenital dislocation of the hip in young children: a clinical and experimental investigation. Can J Surg 1969;12:44-61.

12. Omeroğlu H, Uçar DH, Tümer Y. A new measurement method for the radiographic assessment of the proximal femur: the center-trochanter distance. Acta Orthop Traumatol Turc 2004;38:261-4.

13. Hangody L, Füles P. Autologous osteochondral mosaicplasty for the treatment of full-thickness defects of weight-bearing joints: ten years of experimental and clinical experience. J Bone Joint Surg Am 2003;85-A Suppl 2:25-32.

14. Hangody L, Vásárhelyi G, Hangody LR, Sükösd Z, Tibay G, Bartha L, et al. Autologous osteochondral grafting-technique and long-term results. Injury 2008;39 Suppl 1:S32-9.

15. Nam D, Shindle MK, Buly RL, Kelly BT, Lorich DG. Traumatic osteochondral injury of the femoral head treated by mosaicplasty: a report of two cases. HSS J 2010;6:228-34.

16. Hart R, Janecek M, Visna P, Bucek P, Kocis J. Mosaicplasty for the treatment of femoral head defect after incorrect resorbable screw insertion. Arthroscopy 2003;19:E1-5.

17. Gagala J, Tarczyńska M, Gawęda K. Clinical and radiological outcomes of treatment of avascular necrosis of the femoral head using autologous osteochondral transfer (mosaicplasty): preliminary report. Int Orthop 2013;37:1239-44.

18. Anthonissen J, Rommens PM, Hofmann A. Mosaicplasty for the treatment of a large traumatic osteochondral femoral head lesion: a case report with 2 year follow-up and review of the literature. Arch Orthop Trauma Surg 2016;136:41-6.

19. Güngör HR, Kiter E, Ök N, Çatak A. Osteochondral mosaicplasty along with osteochondroplasty of the femoral head in femoroacetabular impingement: a case report. Eklem Hastalik Cerrahisi 2015;26:181-4.

20. Kılıçoğlu Öİ, Polat G, Erşen A, Birişik F. Long-term result of mosaicplasty for femoral head osteochondral lesion: a case report with 8 years follow-up. Hip Int 2015;25:589-92. 
21. Gagała J, Tarczyńska M, Gawęda K. Fixation of femoral head fractures with autologous osteochondral transfer (mosaicplasty). J Orthop Trauma 2014;28:e226-30.

22. Kubo T, Utsunomiya H, Watanuki M, Hayashi $H$, Sakai A, Uchida S. Hip Arthroscopic Osteochondral Autologous Transplantation for Treating Osteochondritis Dissecans of the Femoral Head. Arthrosc Tech 2015;4:e675-80.

23. Cetinkaya S, Toker B, Taser O. Arthroscopic retrograde osteochondral autologous transplantation to chondral lesion in femoral head. Orthopedics 2014;37:e600-4.

24. Won Y, Lee GS, Kim SB, Kim SJ, Yang KH. Osteochondral
Autograft from the Ipsilateral Femoral Head by Surgical Dislocation for Treatment of Femoral Head Fracture Dislocation: A Case Report. Yonsei Med J 2016;57:1527-30.

25. Louahem D, Lozach F, Delpont M, Weiss A, Prodhomme O, Cottalorda J. Mosaicplasty for femoral osteochondritis dissecans. Orthop Traumatol Surg Res 2016;102:247-50.

26. Emre TY, Cift H, Seyhan B, Ceyhan E, Uzun M. Mosaicplasty for the treatment of the osteochondral lesion in the femoral head. Bull NYU Hosp Jt Dis 2012;70:288-90.

27. Girard J, Roumazeille T, Sakr M, Migaud H. Osteochondral mosaicplasty of the femoral head. Hip Int 2011;21:542-8. 